\title{
Planar Inductor for Biological Experimentation in Pulsed Magnetic Fields
}

\author{
Audrius Lucinskis, Audrius Grainys, Sebastjanas Kurcevskis, Sonata Tolvaisiene, \\ Tomas Ustinavicius, Ricardas Masiulionis, Paulius Butkus \\ Department of Electrical Engineering, Vilnius Gediminas Technical University, \\ Naugarduko St. 41-318, LT-03227 Vilnius, Lithuania \\ audrius.lucinskis@vgtu.lt
}

\begin{abstract}
In this paper we present the novel design of the multilayer planar inductor for biological experimentation in pulsed magnetic fields. The presented planar inductor, together with developed high voltage generator, is capable to deliver $1 \mathrm{~T}$ homogeneous magnetic fields in the volume of $17 \mu \mathrm{l}$ with pulse repetition frequency up to $10 \mathrm{kHz}$. The finite element methods were applied to evaluate the magnetic field distribution and heat dissipation of proposed multilayer planar inductor under aluminium dioxide $\mathrm{Al}_{2} \mathrm{O}_{3}$ substrate. The computed and experimental results are presented as well.
\end{abstract}

Index Terms-Planar inductor; Pulse power; Pulse magnetic field; Finite element method; Biological cell.

\section{INTRODUCTION}

The application of pulsed magnetic fields increased dramatically during last few decades. The scientists and engineers have found the applicability of magnetic fields in areas such as military applications - rail guns [1], [2], food industry - food preservation [3], [4], medicine - "Hall effect" imaging, tomography [5]-[7] biology - delivery of the nanoparticles [8]-[11] or even in space programs active shielding from radiation [12], [13]. One of the novel areas of the application of high pulsed magnetic fields is magnetoporation - permeabilization of the living biological cells using high pulsed magnetic fields. The original and seminal [14]-[17] papers on the permeabilization of living cells using pulsed magnetic fields takes a large interest in scientific society as it can be applied as contactless method of the well-known electroporation phenomenon [18]-[22], when high up to $30 \mathrm{kV} / \mathrm{cm}$ electric fields are applied over cell membrane, which causes an increase of cell transmembrane potential. When the transmembrane potential reaches $200 \mathrm{mV}-1 \mathrm{~V}$, depending on the cell type, the cell membrane becomes permeable to small molecules due to appearance of the permanent nanopores over cell membrane. Despite all the advantages the electroporation application requires tens of kilovolts to be applied, which can lead to cell death [23]-[26].

Therefore, application of high magnetic field pulses with high $d B / d t$, results the induction of the electric field which leads of increase of the membrane potential. In such way magnetoporation allows contactless cell membrane permeabilization without side effects of electroporation [14], [27]-[29].
The existing magnetoporation systems can generate pulsed magnetic fields up to $20 \mathrm{~T}$. To generate such pulsed magnetic fields the complicated pulse forming networks, heavy, large volume and expensive pulsed magnetic field generators with limited transport possibilities are used. Usually these systems are used to investigate the phenomenon itself. Also, the lack of such generators due to their complexity and price impedes their applicability for small research groups or individual researches.

In this paper we present novel multilayer planar inductor together with magnetic field generator for biological experiments in pulsed magnetic fields. The planar technology is well developed, therefore, different forms of inductors can be replicated and produced by photolithography. The proposed assembly of the planar inductor is capable to generate pulsed magnetic fields up to $1 \mathrm{~T}$ with repetition frequency up to $10 \mathrm{kHz}$.

\section{PLANAR INDUCTOR}

\section{A. Geometry}

Figure 1 shows a proposed 3D model of the planar inductor for cell permeabilization in pulsed magnetic fields. The combined and expanded view of the multilayer planar inductor are shown in the figure. As it can be seen from the expanded view, the 4 separate planar inductors are stacked together on the axis of revolution by revolution angle of $90^{\circ}$. The planar inductor is fabricated using photolithography process. Using photolithography technology, the planar inductor can be fabricated on standard FR-4 textolite substrate as well as our proposed aluminium oxide $\mathrm{Al}_{2} \mathrm{O}_{3}$ substrate.

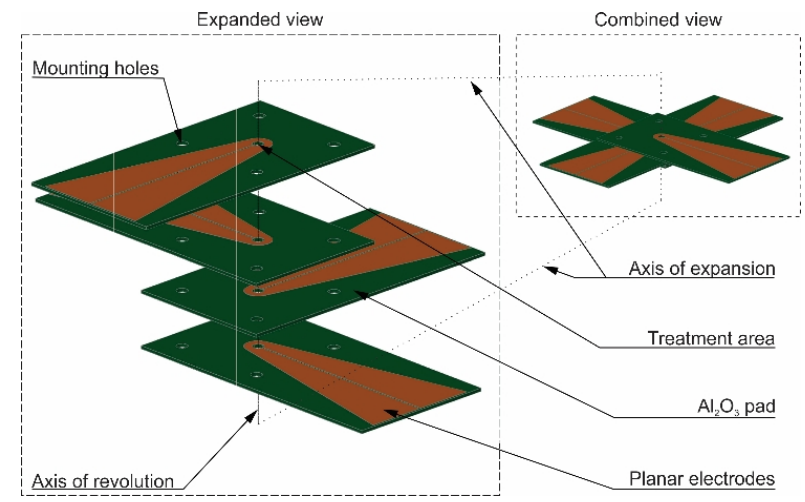

Fig. 1. Expanded and combined view of the novel planar inductor for biological experiments in pulsed magnetic fields. 
As FR-4 as well as $\mathrm{Al}_{2} \mathrm{O}_{3}$ are good insulators, the substrate acts as electrical insulation material between the stacked coils operated under high voltage.

Also, the substrate works as heat sink and protects from overheating during repetitive operation. As the planar technology is well developed, it is easy to replicate the proposed inductor geometry without complex and expensive manufacture techniques, which makes it more accessible for small scientific research groups. After evaluating the standard electroporation cuvette sizes, an inductor with an internal diameter of $3 \mathrm{~mm}$ is selected for the prototype. The metalized layer, in the standard case is $0.1 \mathrm{~mm}$.

It should be noted that proposed geometry of the planar inductor is not limited by the number of the stacked inductors as long as the sufficient heat dissipation from the plates of the inductor is ensured.

The physical parameters of the coil as well as simulation parameters for the magnetic flux density and heat exchange calculation are given in the Fig. 2.

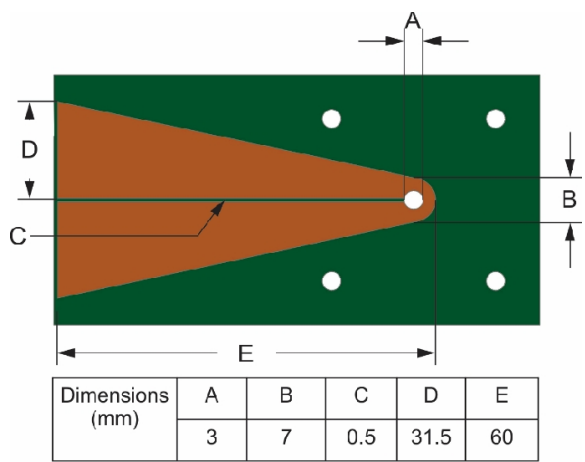

Fig. 2. Physical and mathematical simulation parameters of the proposed planar inductor.

\section{B. Magnetic Field Distribution}

Figure 1 and Fig. 3 shows planar inductor configuration for cell treatment in high pulsed magnetic fields. Referring to both figures, the proposed model of the inductor is modelled as four concentric cylinders placed on the top of each other and depending on simulation parameters separated by textolite FR-4 or $\mathrm{Al}_{2} \mathrm{O}_{3}$ substrates for insolation and heat dissipation purpose.

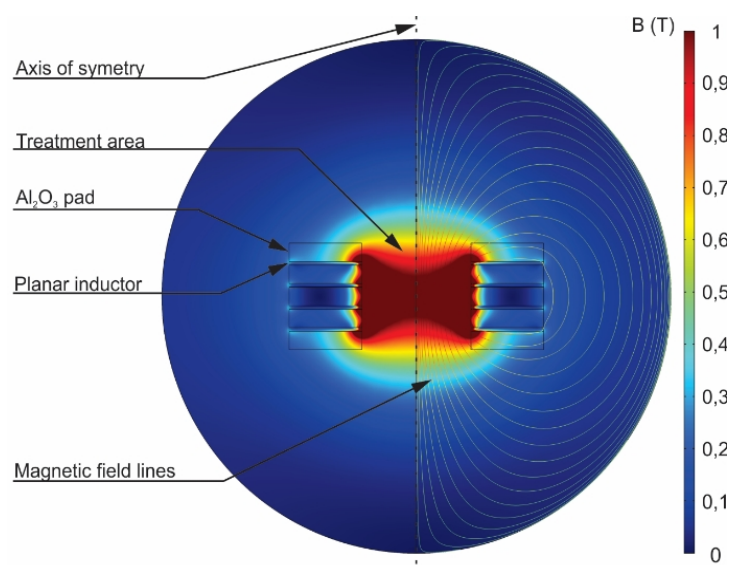

Fig. 3. Magnetic flux density and magnetic field lines.

The simplified mathematical model of the planar inductor was made using "COMSOL Multiphysics" finite element method analysis tool and is presented in Fig. 3. To implement transient parameters of the current pulse, delivered from the pulsed magnetic field generator the timedependent solver for the simulation was chosen. While to evaluate magnetic flux density $B$ the "Magnetic Fields (mf)" physics was chosen. Under this physics module the "Coil Group Domain" was selected to simulate four different coils stacked on the top of each other. The time varying current source was defined as excitation of the coil. The concentric cylinders together with inductor pads are treated as axisymmetric model which, is revolved by $360^{\circ}$ after simulation. As it can be seen from the Fig. 3, the stacked inductor four loops can be described as Helmholtz coil arrangement. The separate magnetic flux densities generated by separate planar inductors can be added by superimposing four constituent fields. The simulation results showed that the homogeneous generated flux density in the volume of $17 \mu l$ is equal to $1 \mathrm{~T}$. The proposed geometry is not limited with the number of the stacked coils and allows of generation of the higher homogeneous magnetic fields in large volumes with adding more planar inductors to the stack. The magnetic field lines for the developed geometry are given in the Fig. 3 .

\section{Heat Dissipation}

In biological experiments as well as in electroporation or magnetoporation, it is important to maintain a constant temperature, or at least to be sure that, the peak temperature does not exceed the permissible limits during the experiments. To estimate the warm-up processes in proposed planar inductor geometry the "COMSOL Multiphysics" finite element method analysis tool was used.

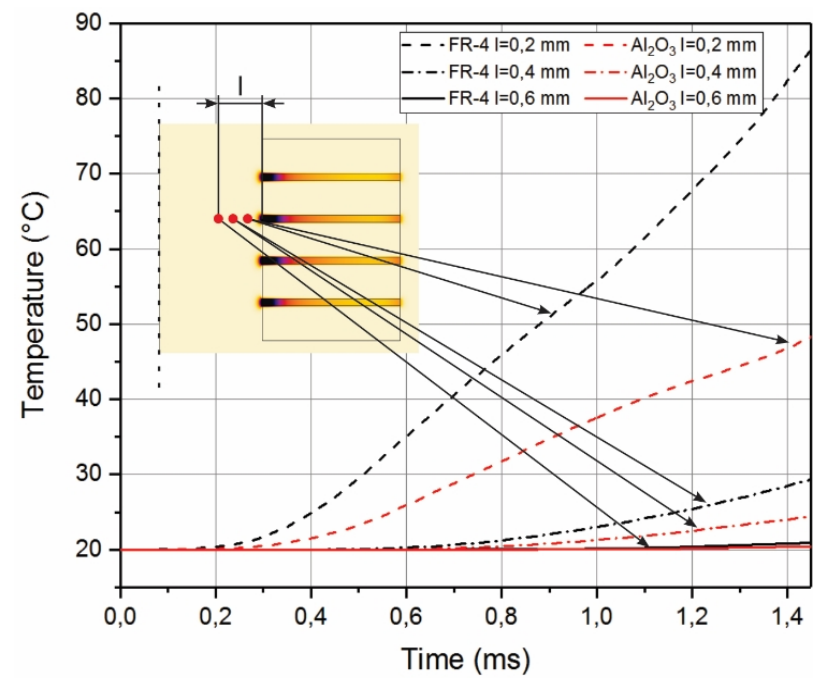

Fig. 4. Mathematical calculations of the heat dissipation in the planar inductor.

The finite element method analysis results are presented in Fig. 4. As it can be seen, in a multilayer planar inductor using a glass textolite (FR-4) insulating material the temperature of $85{ }^{\circ} \mathrm{C}$ can be reached in a distance $l$ of $0.2 \mathrm{~mm}$ from the internal conductor surface when 30 repetitive pulses with duration of $5 \mu$ s are used. Such warming can be negative for the biological objects under investigation. The thermal conductivity of the textolite FR-4 is about $0.4 \mathrm{~W} / \mathrm{mK}$. Therefore, in order to increase the heat transfer in the structure, aluminium oxide $\mathrm{Al}_{2} \mathrm{O}_{3}$ substrates with a thermal conductivity of $24 \mathrm{~W} / \mathrm{mK}$ were proposed instead of the textolite. The results of the warming 
simulation of a multilayer planar inductor on textolite and $\mathrm{Al}_{2} \mathrm{O}_{3}$ pallets are presented in Fig. 4. As we can see the maximal heating using $\mathrm{Al}_{2} \mathrm{O}_{3}$ substrate is dropped by $40{ }^{\circ} \mathrm{C}$ resulting in maximal temperature increase of the $55^{\circ} \mathrm{C}$. Also increasing measurement point distance $l$ from the planar inductor results the temperature increase up to $25{ }^{\circ} \mathrm{C}$ that ensures the sufficient temperature for the biological substances [30].

\section{PROPOSED EXPERIMENTAL SETUP}

\section{A. Magnetic Field Generator}

Figure 5 presents the prototype of pulsed magnetic field generator for biological experiment in pulsed magnetic fields. The proposed pulsed magnetic field generator consists of four independent and galvanically insolated high voltage sources, IGBT switch and a planar inductor that generates a magnetic field. The proposed generator topology together with the multilayer inductor is not limited in number of the coils and generators as each inductor is powered by a separate power source.

The 32 bit. ARM Cortex-M0 microcontroller (LPC1114) generates the signals with the following pulse parameters: pulse width $(10 \mu \mathrm{s}-30 \mu \mathrm{s})$, pulse frequency $(1 \mathrm{kHz}-10 \mathrm{kHz})$ and pulse number (1-999) with an amplitude of $3.3 \mathrm{~V}$. The signal is sent to the galvanically insolated driver which drives two MOSFET (PSMN2R6-40YS) transistors. When microcontroller generates the $3.3 \mathrm{~V}$ signal, left MOSFET transistor (SW2) is $\mathrm{ON}$ and right (SW3) - OFF state. So IGBT (IXYX100N120B3) gate emitter voltage is $+25 \mathrm{~V}$. When IGBT is turned-on, the current flows through the planar Coil. When microcontroller signal is low $(0 \mathrm{~V})$, the left (SW2) transistor of half bridge is turned-off, and right (SW3) - turned-on which results in gate emitter voltage to be $-9 \mathrm{~V}$.

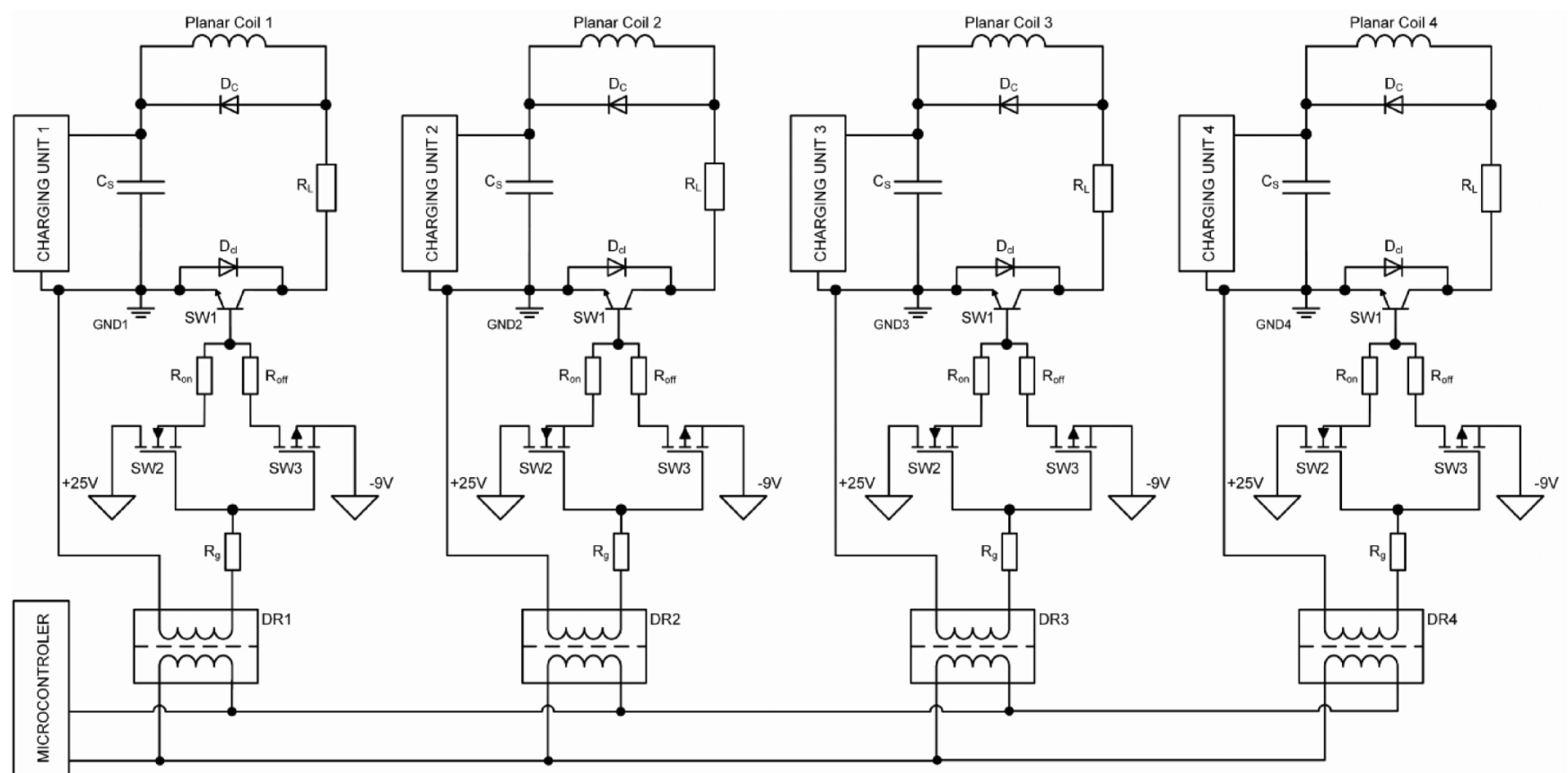

Fig. 5. Simplified schematics of pulsed magnetic field generator for biological experimentation.

Half bridge control system with MOSFET transistors enables to get more powerful driver for IGBT control comparing with ordinary IGBT drivers. During operation, the turn-on and turn-off transients of the IGBT switch take place in case of inductive load. Therefore, clamping diodes should be connected to protect IGBT from transient overloads.

\section{B. Magnetic Field and Heat Dissipation Measurements}

To test simulation results of the pulsed magnetic field and heat dissipation during the field generation the setup of measurement of the magnetic field distribution and heat in the center of the planar inductor is proposed. The simplified circuit of the magnetic field and temperature measurement setup is shown in the Fig. 6.

The proposed magnetic field generator generates magnetic field pulses with duration in microsecond range. To measure such high-gradient magnetic fields, the fast and small in dimensions' magnetic field sensor is required.

As we can see from Fig. 3 the direction of the generated magnetic field is known. Due to this the loop sensor was chosen for axial magnetic field measurement experiments The magnetic field loop sensor was made in Institute of High Magnetic Fields of Vilnius Gediminas Technical University (VGTU, Lithuania) and calibrated using "Lakeshore 455" gaussmeter. The loop sensor was wounded with $0.05 \mathrm{~mm}$ copper wire and consisted of 5 turns placed in the middle of the planar inductor. The signal proportional to $d B / d t$ is integrated and controlled with oscilloscope.

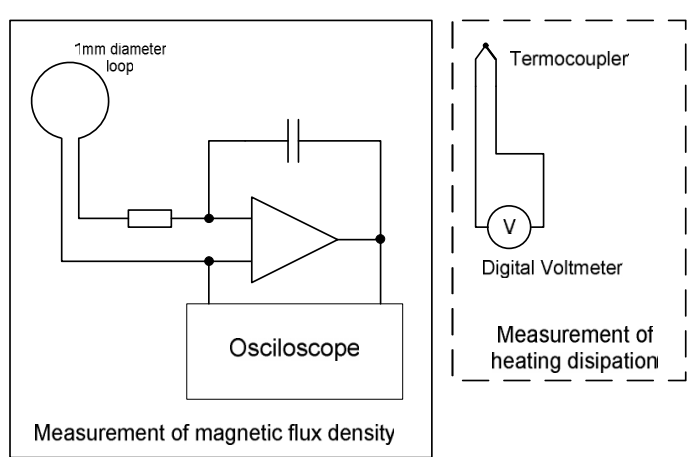

Fig. 6. The magnetic field and temperature measurement setup. 
To evaluate the change of the temperature inside of the planar inductor, the digital multimeter Tektronix DMM4050 together with platinum resistance temperature sensor PT1000 due to its size was chosen. To simulate experimental environment, the planar inductor with aluminum oxide $\mathrm{Al}_{2} \mathrm{O}_{3}$ substrate should be filled with distilled water. The thermocouple PT1000 should be placed in the middle of the inductor.

\section{CONCLUSIONS}

The proposed multilayer planar inductor geometry consisting of four planar inductors with an internal diameter of $3 \mathrm{~mm}$ and outer diameter of $7 \mathrm{~mm}$, together with proposed experimental setup, can generate $<1 \mathrm{~T}$ amplitude pulsed magnetic field. According to finite element method analysis, for the better treatment area heat exchange characteristics the aluminum oxide $\mathrm{Al}_{2} \mathrm{O}_{3}$ substrates instead of the textolite FR-4 are recommended to increase the heat transfer. The warm-up of the multilayer pulsed inductor on the aluminium oxide $\mathrm{Al}_{2} \mathrm{O}_{3}$ substrate is $40{ }^{\circ} \mathrm{C}$ lower than the prototype of the textolite, which can have an impact on results of the biological experiment.

\section{REFERENCES}

[1] O. Liebfried, V. Brommer, "A four-stage xram generator as inductive pulsed power supply for a small-caliber railgun", IEEE Trans. Plasma Sci., vol. 41, no. 10, pp. 2805-2809, 2013. DOI: 10.1109/TPS.2013.2257873.

[2] M. Schneider, O. Liebfried, V. Stankevic, S. Balevicius, N. Zurauskiene, "Magnetic diffusion in railguns: Measurements using CMR-based sensors", in IEEE Trans. Magnetics, 2009, vol. 45, no. 1, pp. 430-435. DOI: 10.1109/TMAG. 2008.2008539.

[3] N. Grigelmo-Miguel, R. Soliva-Fortuny, G. V. Barbosa-Canovas, O. Martin-Belloso, "Use of oscillating magnetic fields in food preservation", in Nonthermal Processing Technologies for Food, 2011, pp. 222-235. DOI: 10.1002/ 9780470958360.ch16.

[4] C. T. Yavuz, A. Prakash, J. T. Mayo, V. L. Colvin, "Magnetic separations: From steel plants to biotechnology", Chemical Engineering Science, vol. 64, no. 10. pp. 2510-2521, 2009. DOI: 10.1016/j.ces.2008.11.018.

[5] I. Lopez Costa, S. Bhalla, "Computed tomography and magnetic resonance imaging of the pericardium", Semin. Roentgenol., vol. 43 , no. 3, pp. 234-245, 2008. DOI: 10.1053/j.ro.2008.02.008.

[6] M. Kranjc, F. Bajd, I. Sersa, D. Miklavcic, "Magnetic resonance electrical impedance tomography for monitoring electric field distribution during tissue electroporation", IEEE Trans. Med. Imaging, vol. 30 , no. 10, pp. 1771-1778, 2011. DOI: 10.1109/TMI.2011.2147328.

[7] H. Wen, J. Shah, R. S. Balaban, "Hall effect imaging," IEEE Trans. Biomed. Eng., vol. 45, no. 1, pp. 119-124, 1998. DOI: 10.1109/10.650364.

[8] A. Kolin, "Magnetic fields in biology", Phys. Today, vol. 21, no. 11, pp. 39-50, 1968. DOI: 10.1063/1.3034587.

[9] Q. A. Pankhurst, J. Connolly, S. K. Jones, J. Dobson, “Applications of magnetic nanoparticles in biomedicine", Journal of Physics D: Applied Physics, vol. 36, no. 13, 2003. DOI: 10.1088/00223727/36/13/201.

[10] J. Miyakoshi, "Effects of static magnetic fields at the cellular level", Progress in Biophysics and Molecular Biology, 2005, vol. 87, no. 2-3 pp. 213-223. DOI: 10.1016/ j.pbiomolbio.2004.08.008.

[11] V. F. Cardoso, A. Francesko, C. Ribeiro, M. Banobre-Lopez, P. Martins, S. Lanceros-Mendez, "Advances in magnetic nanoparticles for biomedical applications", Adv. Healthc. Mater., vol. 7, no. 5, p. 1700845, 2018. DOI: 10.1002/adhm.201700845.

[12] L. W. Townsend, "Overview of active methods for shielding spacecraft from energetic space radiation", Phys. Med., vol. 17, no. 1, pp. 84-5, 2001.

[13] P. Spillantini et al., "Shielding from cosmic radiation for interplanetary missions: Active and passive methods", Radiat. Meas., vol. 42, no. 1, pp. 14-23, 2007. DOI: 10.1016/j.radmeas.2006.04.028.

[14] S. Markovskaja, V. Novickij, A. Grainys, J. Novickij, "Irreversible magnetoporation of micro-organisms in high pulsed magnetic fields", IET Nanobiotechnology, vol. 8, no. 3, pp. 157-162, 2014. DOI: 10.1049/iet-nbt.2013.0005.

[15] D. Liu, L. Wang, Z. Wang, A. Cuschieri, "Magnetoporation and magnetolysis of cancer cells via carbon nanotubes induced by rotating magnetic fields", Nano Lett., vol. 12, no. 10, pp. 5117-5121, 2012. DOI: $10.1021 / \mathrm{nl} 301928 \mathrm{z}$.

[16] V. Novickij, A. Grainys, G. Staigvila, S. Tolvaisiene, T. Ustinavicius, J. Novickij, "Design and optimization of pulsed magnetic Field generator for cell magneto-permeabilization", Elektronika ir Elektrotechnika, vol. 23, no. 2, pp. 21-25, 2017. DOI 10.5755/j01.eie.23.2.17994.

[17] T. Pourmirjafari Firoozabadi, Z. Shankayi, A. Izadi, S. M. Pourmirjafari Firoozabadi, "Can Lucifer yellow indicate correct permeability of biological cell membrane under an electric and magnetic field?", Cell J., vol. 16, no. 4, pp. 560-3, 2015. DOI: 10.22074/cellj.2015.501

[18] H. Nakamura, J. Funahashi, "Electroporation: Past, present and future", Dev. Growth Differ., 2012. DOI: 10.1111/dgd.12012.

[19] C. Chen, S. W. Smye, M. P. Robinson, J. A. Evans, "Membrane electroporation theories: A review", Medical and Biological Engineering and Computing, vol. 44, no. 1-2. pp. 5-14, 2006. DOI: 10.1007/s11517-005-0020-2

[20] T. Y. Tsong, "Electroporation of cell membranes", Biophysical Journal, vol. 60, no. 2. pp. 297-306, 1991. DOI: 10.1016/S00063495(91)82054-9.

[21] J. Gehl, "Electroporation: theory and methods, perspectives for drug delivery, gene therapy and research", Acta Physiol. Scand., vol. 177, no. 4, pp. 437-47, 2003. DOI: 10.1046/j.1365-201X.2003.01093.x.

[22] V. Novickij, P. Ruzgys, A. Grainys, S. Satkauskas, "High frequency electroporation efficiency is under control of membrane capacitive charging and voltage potential relaxation", Bioelectrochemistry, vol. 119, pp. 92-97, 2018. DOI: 10.1016/j.bioelechem.2017.09.006.

[23] M. Rebersek, D. Miklavcic, "Advantages and disadvantages of different concepts of electroporation pulse generation," Automatika, vol. 52, no. 1, pp. 12-19, 2011. DOI: 10.1109/TBME.2014.2367543.

[24] O. Seror, "Ablative therapies: Advantages and disadvantages of radiofrequency, cryotherapy, microwave and electroporation methods, or how to choose the right method for an individual patient?", Diagn Interv. Imaging, vol. 96, no. 6, pp. 617-624, 2015. DOI 10.1016/j.diii.2015.04.007

[25] R. V. Davalos, L. M. Mir, B. Rubinsky, "Tissue ablation with irreversible electroporation", Ann. Biomed. Eng., vol. 33, no. 2, pp. 223-231, 2005. DOI: $10.1007 / \mathrm{s} 10439-005-8981-8$.

[26] M.-S. Wang et al., "A review of sublethal effects of pulsed electric field on cells in food processing", J. Food Eng., vol. 223, pp. 32-41, 2018. DOI: 10.1016/j.jfoodeng. 2017.11.035.

[27] T. J. Kardos, D. P. Rabussay, "Contactless magneto-permeabilization for intracellular plasmid DNA delivery in-vivo", Hum. Vaccin. Immunother., vol. 8, no. 11, pp. 1707-1713, 2012. DOI: $10.4161 / \mathrm{hv} .21576$

[28] S. Kranjc, M. Kranjc, J. Scancar, J. Jelenc, G. Sersa, D. Miklavcic, "Electrochemotherapy by pulsed electromagnetic field treatment (PEMF) in mouse melanoma B16F10 in vivo.", Radiol. Oncol., vol. 50, no. 1, pp. 39-48, 2016. DOI: 10.1515/raon-2016-0014.

[29] L. Towhidi, S. M. P. Firoozabadi, H. Mozdarani, D. Miklavcic, "Lucifer Yellow uptake by $\mathrm{CHO}$ cells exposed to magnetic and electric pulses", Radiol. Oncol., vol. 46, no. 2, pp. 119-25, 2012. DOI: $10.2478 / \mathrm{v} 10019-012-0014-2$.

[30] V. Novickij, A. Grainys, J. Svediene, S. Markovskaja, J. Novickij, "Joule heating influence on the vitality of fungi in pulsed magnetic fields during magnetic permeabilization", J. Therm. Anal. Calorim., vol. 118 , no. 2, pp. 681-686, 2014. DOI: 10.1007/s10973-014-37351. 